\title{
Study of Diffusion through the Skin of Coated L-Ascorbic Acid by Fluid Bed Technology
}

\author{
Ferrándiz Marcela, Capablanca Lucía \\ Biotechnology Research Group, Textile Research Institute (AITEX), Alcoy, Spain \\ Email:mferrandiz@aitex.es
}

How to cite this paper: Marcela, F. and Lucía, C. (2017) Study of Diffusion through the Skin of Coated L-Ascorbic Acid by Fluid Bed Technology. Journal of Encapsulation and Adsorption Sciences, 7, 75-82. https://doi.org/10.4236/jeas.2017.72005

Received: April 3, 2017

Accepted: June 5, 2017

Published: June 12, 2017

Copyright $\odot 2017$ by authors and Scientific Research Publishing Inc. This work is licensed under the Creative Commons Attribution International License (CC BY 4.0).

http://creativecommons.org/licenses/by/4.0/

\begin{abstract}
Coating protects substances such as L-ascorbic acid from natural processes like oxidation. In this study, L-ascorbic acid was coated by fluid bed technology. A pH-dependent polymer was used as a coating material in order to release L-ascorbic acid (dissolution above $\mathrm{pH}$ 5.5) under conditions closest to the skin's natural condition. Different techniques were used to determine the coating (SEM and size distribution) and to evaluate the percentage of coated L-ascorbic acid and its diffusion through the skin.
\end{abstract}

\section{Keywords}

pH Dependent Polymer, L-Acid Ascorbic, Diffusion, Fluid Bed

\section{Introduction}

Vitamin C (Vit. C) is one of the naturally occurring antioxidants in nature. Most plants and animals are able to synthesise Vit. C in vivo from glucose [1].

$\mathrm{L}$-ascorbic acid (LAA) is the chemically active form of Vit. C. In nature, Vit. C is found in equal parts as LAA and D-ascorbic acid. These are essentially isomeric molecules and are mutually interchangeable. However, only LAA is biologically active and thus useful in medical practice. The absorption of Vit. C in the gut is limited by an active transport mechanism and hence a finite amount of the drug is absorbed despite high oral dosage. Furthermore, bioavailability of Vit. C in the skin is inadequate when it is administered orally. The use of topical ascorbic acid is therefore favored in the practice of dermatology [1].

Ascorbic acid is used as an ingredient of anti-aging cosmetic products. As an antioxidant, it protects the skin by neutralizing reactive oxygen species (ROS) generated on exposure to sunlight. In biological systems, it reduces both oxygenand nitrogen-based free radicals and thus delays the aging process [2].

The use of ascorbic acid in cosmetic and pharmaceutical products is however 
limited due to its low stability [3]. Ascorbic acid is a very unstable vitamin and is easily oxidized in aqueous solutions and cosmetic formulations.

To solve this problem of stability different strategies are being studied and the microencapsulation is a suitable technology.

Microencapsulation technology provides a strategy for enhancing retention of sensitive and expensive active components, including LAA through protection from adverse conditions and allowing delivery to the target site at the required time. Microcapsules have the potential to be very widely used in cosmetic industry applications and some of these are microencapsulation can protect sensitive core compounds from the environmental factors, including oxygen, water and light; undesirable interactions with other ingredients; other roles are to control diffusion or to isolate or control the release of an encapsulated active compounds at the right place and the right time [4].

There are a number of commercially approved shell materials available to produce various microencapsulated Not all shell materials meet all the properties needed, so they are often used in combination with other coating materials with other modifiers such as oxygen scavengers, antioxidants, chelating agents and surfactants [5].

Some microencapsulated materials are made for controlled release of the microencapsulant, perhaps during processing, storage or during final preparation prior to consumption. Commonly used methods for controlled release include temperature and moisture release for hydrophilic encapsulants. Other release methods include $\mathrm{pH}$ control, addition of surfactants, enzymatic release, ultrasonics, grinding, and photo-release [5].

There are numerous methods for microencapsulation of active compounds but no single encapsulation process is adaptable to all core materials or product applications. The encapsulation of ascorbic acid has been studied using different encapsulation methos: spray drying [6] [7], liposomes [8], inclusion [9], emulsification [10], etc.

In this work Fluidised Bed Coating method has been selected. This process is also known as air suspension coating. It is accomplished by suspending solid particles of the core material in an upward moving stream of air, which can be heated or cooled [5] [11].

A thin layer of coating is deposited onto the core material and full coverage is achieved by multiple passes through the air stream. Optimum encapsulation results are obtained with core particle sizes of between 50 and 500 microns.

The two most important processing variables in this process are volume of fluidized air used, which controls the height of the substrate particles in the air stream and determines their surface coating time. The other variable is air temperature. This is a critical factor as improper temperature control will result in incomplete coverage by the coating material and thus lead to a poor quality product [12]. This method is common for use in the nutritional supplement market to supply encapsulated versions of vitamins [13].

The purpose of this current study has been focused upon the influence of 
coating parameters on the properties of encapsulated ascorbic acid. Morphology, particle size distribution, ascorbic acid content and diffusion were evaluated.

\section{Materials and Methods}

\subsection{Materials}

A copolymer derived from esters of acrylic and methacrylic acid that allows pH-dependent release of the active ingredient, EUDRAGIT L30 D-55 (supplied by Evonik, Germany), was used as shell material.

The core material was L-ascorbic acid (supplied by Sigma Aldrich, Spain).

\subsection{Methods}

Coating was realized in a fluid bed reactor (Uniglatt, Germany). Coating polymer was sprayed at the bottom of the reactor with help of peristaltic pump.

Particles were introduced in the reactor. Air ventilator was run. Spray was started when temperature was stabilized in the reactor (generally $25^{\circ} \mathrm{C}$ ). After end of spraying, reactor was let stand running to finalize particle drying. Then particles were collected and analyzed.

The fixed variables were: in-process air flow $22.0 \mathrm{~m}^{3} / \mathrm{h}$, speed of coating material intake $8 \mathrm{rpm}$, intake air pressure for spraying 1 Bar.

\section{Characterization Tests}

\subsection{Determination of Microcapsules Morphology, Scanning Electron Microscopy (SEM)}

For surface observation, a PHENON scanning electron microscope (FEI company, United States) was used. Each sample studied, LLA uncoated and particles coating, was fixed on a standard sample holder and sputter coated with gold. Samples were then examined with suitable acceleration voltage and magnification. different samples were analyzed in order to select the most representative.

\subsection{Particle-Size Distribution (Mastersizer)}

Mastersizer E 3000 (Malvern Instruments Ldt, UK) is a particle-size analyst. It measures the particle-size distribution due to the measurement of dispersed light intensity. This fact occurs when a laser goes through the dispersed sample of particles. A unit of dispersion for dry samples was used.

\subsection{Determination of LAA in the Microcapsules by Chromatography}

LAA was determined using a Waters chromatograph, fitted with a Waters automatic injector 717 plus, Waters 600 pump and Waters 996 diode detectors, and data was handled using Empower. A Symmetry C18 $(3.9 \times 150 \mathrm{~mm}, 5 \mu \mathrm{m})$ column was used and as a mobile phase a mix of methanol:dihydrogen sodium phosphate $0.05 \mathrm{M}$, with $\mathrm{pH}$ adjusted to 2.5 with phosphoric acid $0.05 \mathrm{M}$. The proportions used were 35 methanol: 65 phosphate, expressed as a volume at a 
flow rate of $0.8 \mathrm{ml} / \mathrm{min}$. injection volume was $20 \mu \mathrm{l}$ and detection wavelength was $244 \mathrm{~nm}$.

The corresponding LAA calibration curve was prepared using as a standard a solution of $500 \mu \mathrm{g} / \mathrm{ml}$ in methanol as a standard and performing dilutions in mobile phase, to obtain a primary standard from 0.195 to $50 \mu \mathrm{g} / \mathrm{ml}$ : all samples and solutions were stored away from light at all times.

\subsection{Trans-Membrane Diffusion Trial}

A test was designed to evaluate LAA diffusion from microcapsules using Franz-type vertical diffusion cells to simulate the skin, with a cellulose-acetate membrane of $0.45 \mu \mathrm{m}$ and $25 \mathrm{~mm}$ diameter, separating the donor compartment from the receptor compartment. The sample of $10 \mathrm{mg}$ of microcapsules dispersed in a buffer solution of phosphate $\mathrm{pH} 7.4$ was placed in the donor compartment. The receptor compartment was filled with a phosphate $\mathrm{pH} 7.4$ buffer solution (approx. $6 \mathrm{~mL}$ ) and a small mixing wand was inserted. The receptor compartments were maintained at $37^{\circ} \mathrm{C} .1 \mathrm{~mL}$ samples were removed at pre-established intervals from the receptor compartment, and the same volume of phosphate $\mathrm{pH} 7.4$ buffer solution was introduced to replace the lost volume. The trial was run with two microcapsule samples for 24 hours, and the accumulated quantity of ascorbic acid in the receptor medium was quantified using the HPLC method described in Paragraph 3.3.

\section{Results and Discussion}

\subsection{Scanning Electron Microscopy (SEM)}

The morphology of the coating was studied by scanning electron microscopy (SEM). Figure 1(a) shows the micrograph of LAA uncoated and Figure 1(b) shows the micrograph of LAA coated by fluid bed.

Comparing SEM images of the coated and uncoated particles, it can be seen that coating layer was deposited on the particles homogenously. They are rounder and the edges of the particles have disappeared: post-coating morphology is completely different.

\subsection{Particle-Size Distribution (Mastersizer)}

The SEM images analyzed previously demonstrated the appearance of a coating, and although the size was determined as variable and it could have been estimated, the particle size test offers objective and more precise measurements. Figure 2 compare the size distribution for LLA uncoated and coated, in order to affirm that exist the coating.

As can be seen in Figure 2, microparticle size is greater in coated particles, confirming the existence of the coating.

The following Table 1 shows the most frequently-repeated value for each sample.

This indicates that particle size has been increased by around 40 times. 


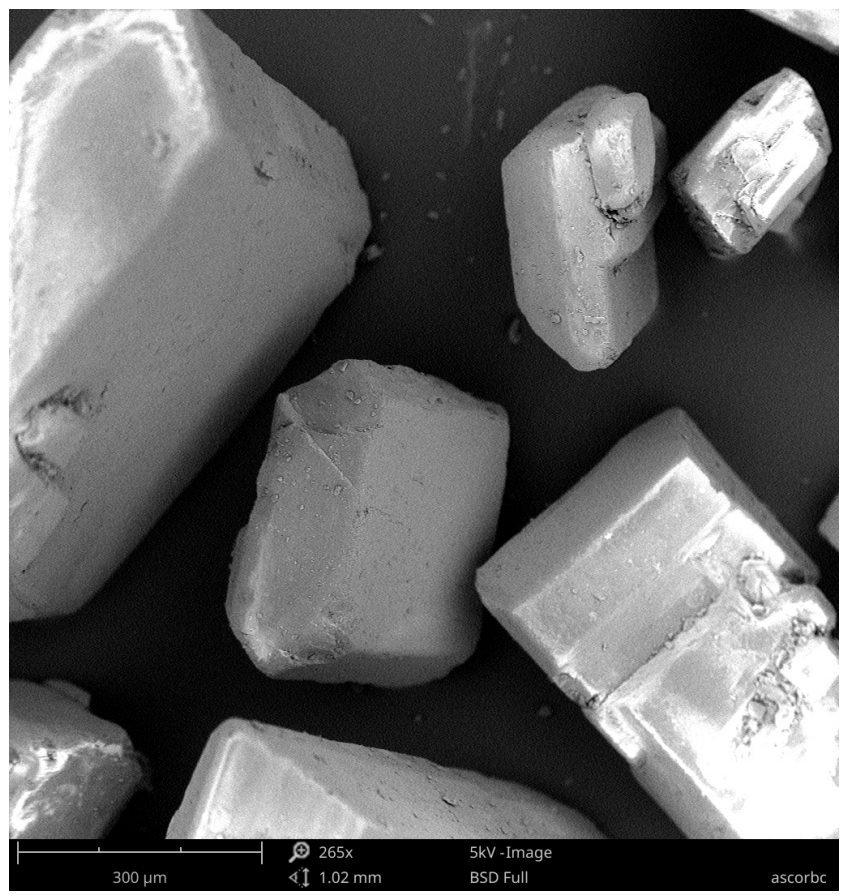

(a)

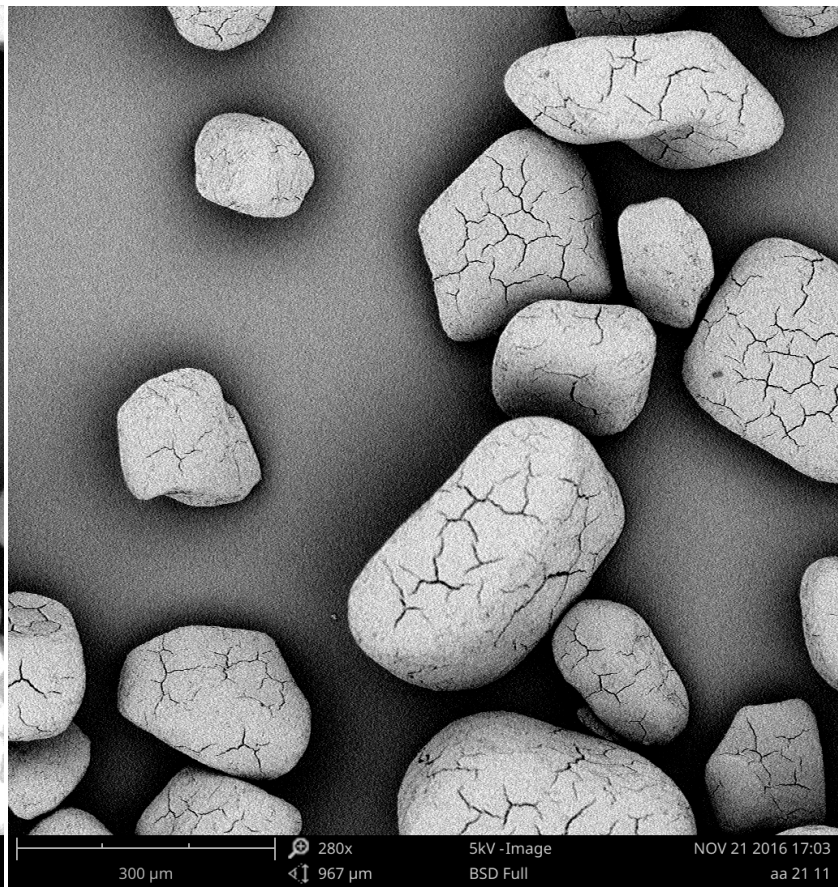

(b)

Figure 1. SEM photographs of (a) LAA uncoated $(\times 265)$ and (b) LLA coated $(\times 280)$.

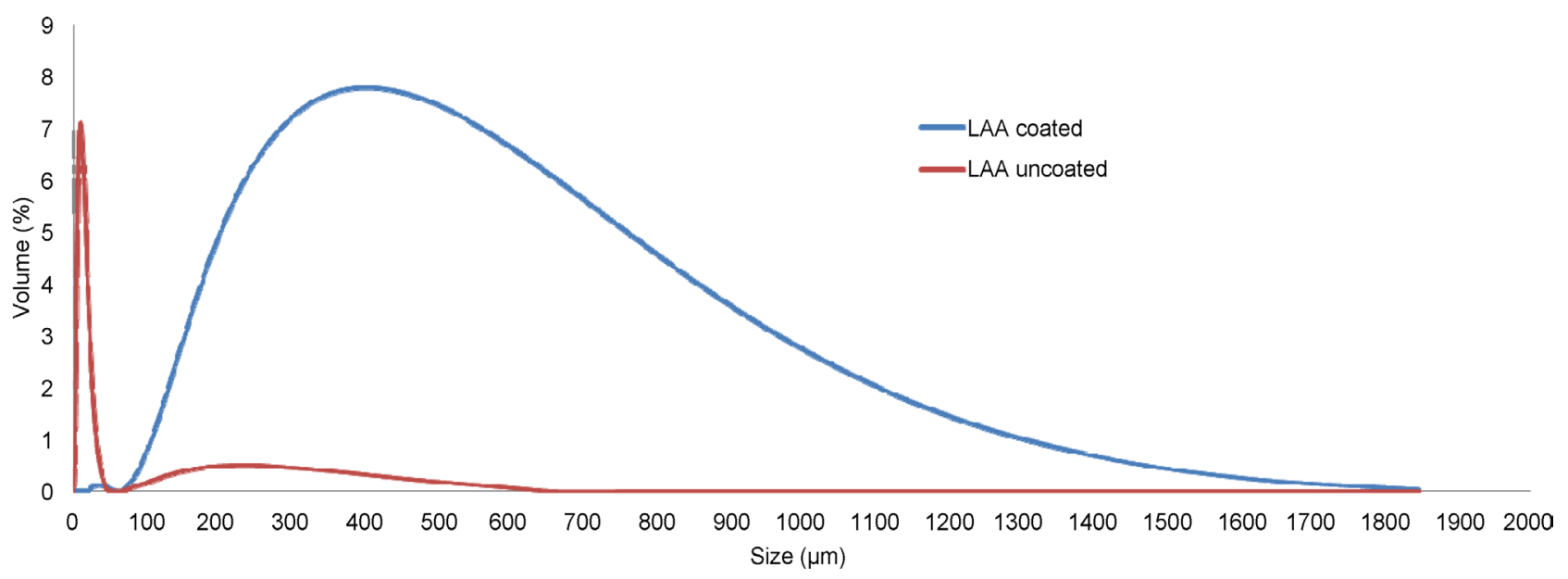

Figure 2. Size distribution.

Table 1. Most frequently-repeated value in the data set.

\begin{tabular}{cc}
\hline LAA uncoated & $10.39 \mu \mathrm{m}$ \\
LAA coated & $429.19 \mu \mathrm{m}$ \\
\hline
\end{tabular}

\subsection{Determination of LAA in the Microcapsules by Chromatography}

The calibration curve is shown in Figure 3.

Coated ascorbic acid was determined by dissolving the sample in methanol and a buffer solution of phosphate, $\mathrm{pH}$ 7.4. The result is $60.14 \% \pm 1.37 \%$ referring to the weight of dry-powder weight of the microparticles. 


\subsection{Trans-Membrane Diffusion Trial}

The resulting diffusion profiles expressed as a total accumulated quantity and as an accumulated percentage are shown in Figure 4 and Figure 5.

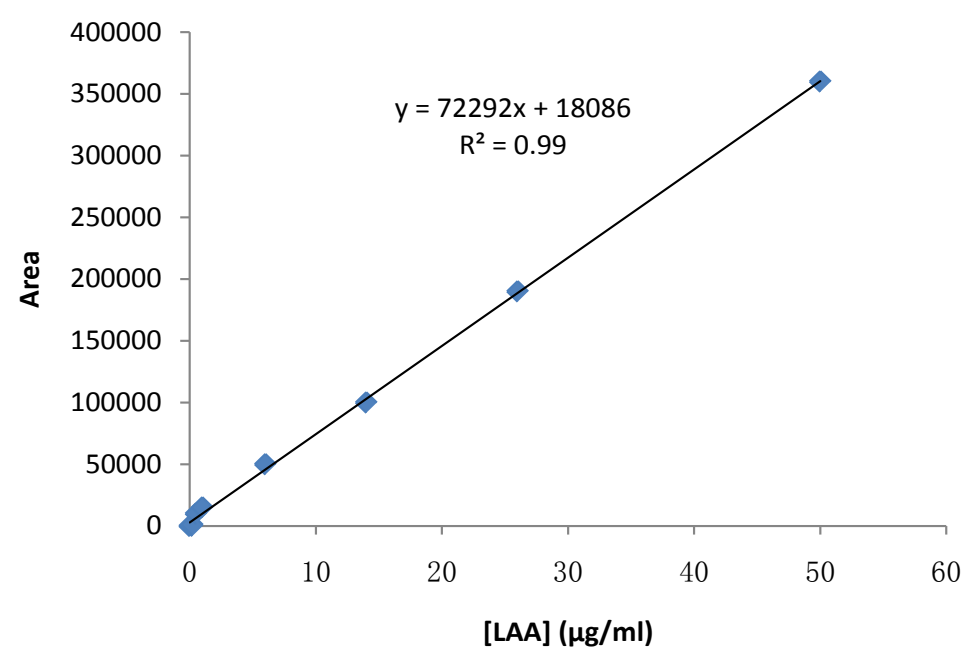

Figure 3. Ascorbic acid calibration curve.

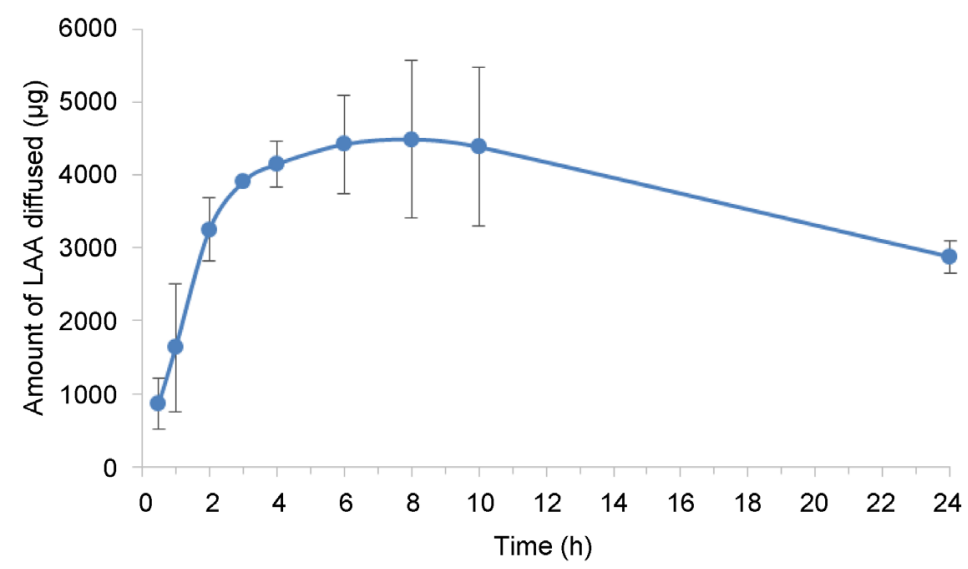

Figure 4. Accumulated ascorbic acid quantities diffused through the microcapsules (average values after two repetitions).

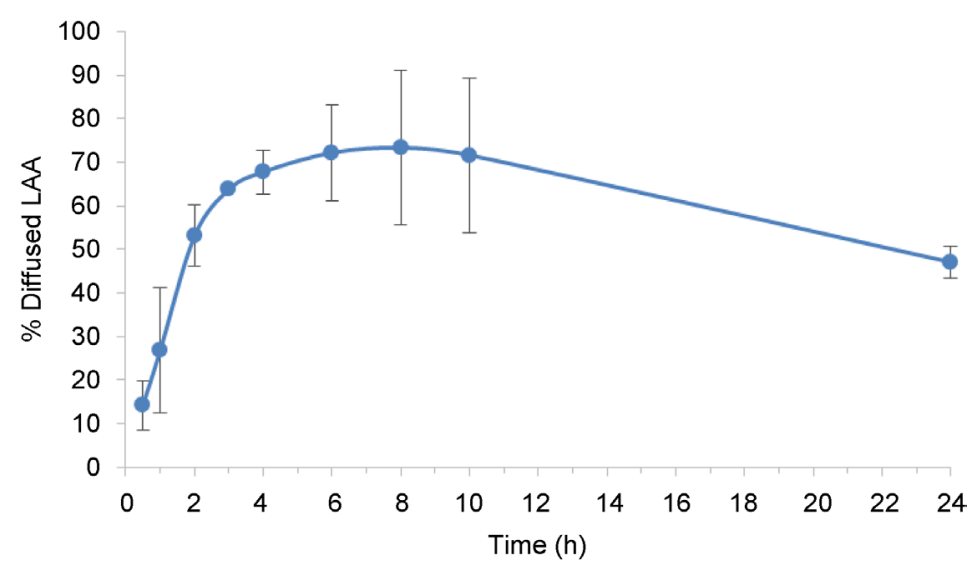

Figure 5. Accumulated ascorbic acid percentages diffused through the microcapsules (average values after two repetitions). 
As can be seen in the above graphs, the coating dissolves upon contact with the $\mathrm{pH} 7.4$ buffer solution, releasing LAA which diffuses rapidly through the membrane: in two hours, more than $50 \%$ of the LAA has diffused.

The reduction in concentration observed after 10 hours may be related to the instability of the ascorbic acid in the medium [14] [15]. Therefore, L-ascorbic acid degrades unavoidably in aqueous solution [16].

\section{Conclusions}

Ascorbic acid, or Vitamin C, is an essential nutrient in the development and repair of tissue, as well as being an antioxidant which slows down the ageing process caused by the damage from free radicals.

The instability of ascorbic acid has led to the use, in cosmetic products, of more stable derivatives which do not oxidise so readily.

Coating ascorbic acid particles protects them from oxidation and permits slow release upon contact with the skin, making it an ideal formulation for use in cosmetic products.

Coating of LAA using a fluid bed and a polymer control release $\mathrm{pH}$ dependent as the coating was feasible for obtaining a protective coating. The microparticles showed high encapsulation efficiency and excellent performance with respect to LAA protection.

The experiment in which the slow release of LAA was determined under strict $\mathrm{pH}$ conditions demonstrates the ability of LAA to be released from microparticles and absorbed by the skin.

\section{Acknowledgements}

The authors thank for the financial support provided by IVACE (Institut Valencià de Competitivitat Empresarial, Spain) and FEDER (Fondo Europeo de Desarrollo Regional, Europe). And thank for technical and human support provided by Dra. Carmen Álvaro Lorenzo from USC.

\section{References}

[1] Telang, P. (2013) Vitamin C in Dermatology. Indian Dermatology Online Journal, 4, 143-146. https://doi.org/10.4103/2229-5178.110593

[2] Sheraz, M.A., Ahmed, S., Ahmad, I. and Shaikh, RH. (2001) Formulation and Stability of Ascorbic Acid in Topical Preparations. Systematic Reviews in Pharmacy, 2, 86-90. https://doi.org/10.4103/0975-8453.86296

[3] Smaoui, S., Ben Hlima, H. and Kadri, A. (2013) Application of L-Ascorbic Acid and Its Derivatives (Sodium Ascorbyl Phosphate and Magnesium Ascorbyl Phosphate) in Topical Cosmetic Formulations: Stability Studies. Journal of the Chemical Society of Pakistan, 35, 1096-1102.

[4] Desai, K.G.H. and Park, H.J. (2005) Recent Developments in Microencapsulation of Food Ingredients. Drying Technology, 23, 1361-1394. https://doi.org/10.1081/DRT-200063478

[5] Wilson, N. and Shah, N.P. (2007) Microencapsulation of Vitamins. ASEAN Food Journal, 14, 1-14. 
[6] De Souzaa, C. and Siqueiraa, S. (2015) Spray-Drying: Preparação, caracterização e atividade antioxidante. Química Nova, 38, 877-883.

[7] Ozsagiroglu, E., Avcibasi Guvenilir, Y., et al. (2016) Production of Polycaprolactone-Polyethylene Glycol-Sodium Alginate Biocomposites for Spray Drying Encapsulation of L-Ascorbic Acid. Iranian Polymer Journal, 25, 757-763.

https://doi.org/10.1007/s13726-016-0464-2

[8] Davis, J.L., Paris, H., et al. (2016) Liposomal-Encapsulated Ascorbic Acid: Influence on Vitamin C Bioavailability and Capacity to Protect against Ischemia-Reperfusion Injury. Nutrition and Metabolic Insights, 9, 25-30.

[9] Revuelta, M.V., et al. (2011) AA Encapsulated in Hydrophobic Silica Xerogel. Food Technology and Biotechnology, 49, 347-351.

[10] Khalida, N. and Kobayashia, I. (2014) Monodisperse W/O/W Emulsions Encapsulating L-Ascorbic Acid: Insights on Their Formulation Using Microchannel Emulsification and Stability Studies. Colloids and Surfaces A: Physicochemical and Engineering Aspects, 458, 69-77.

[11] Poncelet, D., Prata, A.S. and El Mafadi, S. (2009) Optimisation and Process Control of Fluid Bed Coating. XVIIth International Conference on Bioencapsulation, Netherlands.

[12] Risch, S.J. and Reineccius, G.A., Eds. (1995) Encapsulation and Controlled Release of Food Ingredients. American Chemical Society, USA.

https://doi.org/10.1021/bk-1995-0590

[13] Hemati, M., Cherif, R., Saleh, K. and Pont, V. (2003) Fluidized Bed Coating and Granulation: Influence of Process-Related Variables and Physicochemical Properties on the Growth Kinetics. Powder Technology, 130, 18-34. https://doi.org/10.1016/S0032-5910(02)00221-8

[14] Hacişevkđ, A. (2009) An Overview of Ascorbic Acid Biochemistry. Ankara Universitesi Eczacilik Fakultesi Dergisi, 38, 233-244.

[15] Yuan, J.-P. and Chen, F. (1998) Degradation of Ascorbic Acid in Aqueous Solution. Journal of Agricultural and Food Chemistry, 46, 5078-5092. ttps://doi.org/10.1021/jf9805404

[16] Lee, J.-S. and Kim, J.-W. (2004) The Stabilization of L-Ascorbic Acid in Aqueous Solution and Water-in-Oil-in-Water Double Emulsion by Controlling $\mathrm{pH}$ and Electrolyte Concentration. Journal of Cosmetic Science, 55, 1-12. 
Submit or recommend next manuscript to SCIRP and we will provide best service for you:

Accepting pre-submission inquiries through Email, Facebook, LinkedIn, Twitter, etc. A wide selection of journals (inclusive of 9 subjects, more than 200 journals)

Providing 24-hour high-quality service

User-friendly online submission system

Fair and swift peer-review system

Efficient typesetting and proofreading procedure

Display of the result of downloads and visits, as well as the number of cited articles Maximum dissemination of your research work

Submit your manuscript at: http://papersubmission.scirp.org/

Or contact jeas@scirp.org 